\title{
Hyperinsulinemic Hypoglycemia Secondary to Multiple $\beta$ Cell Adenomas in a Boxer Bitch
}

\author{
Ignacio Netzahualcoyotl Barajas-López', Jesús Aurelio Medina-Flores², Gabriela Arnaud-Pérez², \\ Marco Antonio Mendoza-Rivera², Yurixhi López-García², \\ Diana Marcela Beristain-Ruiz ${ }^{3}$ \& Carlos Arturo Rodríguez-Alarcón ${ }^{3}$
}

\begin{abstract}
Background: The most frequent pancreatic tumours are derived from insulin-secreting $\beta$ cells, commonly called insulinomas; these are characterised by high insulin secretion causing hypoglycemia and clinical signs such as seizures, tremors, weakness, and polyphagia, among others. In dogs, this tumour represents $<0.5 \%$ of neoplasias; the majority are solitary carcinoma masses and rarely adenomas. Insulin-secreting tumours are usually diagnosed in middle-aged or older dogs. There is no apparent sex predilection for the disease and it has been mainly reported in medium to large breeds. Independently of whether they are adenomas or carcinomas, dogs have the same disease-free time and survival time and the prognosis is poor.

Case: An 8-year-old female Boxer was brought to the University Veterinary Hospital with a history of weakness, tremors, and generalised convulsions. Physical examination, CBC and urinalysis revealed no abnormalities. In the blood chemistry profile, hypoglycemia was detected along with hyperinsulinemia. An abdominal ultrasound revealed the presence of two abnormal masses located in the pancreas. The insulin:glucose ratio was 59.8. Exploratory celiotomy was performed and two masses were located in the mesentery, adjacent to the left pancreatic lobe, and a third was in the pancreatic tissue of the same lobule. All masses were resected during the same surgery. Cytology of the masses coincided with apparently malignant insulinoma, however, the histopathological and immunohistochemically report indicated an insulin-secreting adenoma. The patient improved clinically and remained stable for approximately 545 days, after which seizures relapsed and a new treatment was not approved. The patient died 575 days after surgery.

Discussion: In dogs, pancreatic islet cell tumours correspond to endocrinologically active neoplasm that secrete hormones and are associated with functional disorders (hyperinsulinemia) in relation to hypoglycemia. Hypoglycemia causes episodic signs that are generally observed for a few seconds to several minutes, because of regulatory compensatory mechanisms. In animals, rapid hypoglycaemia activates the sympathetic nervous system via hypothalamic glucoreceptors, producing signs such as tachycardia, tremors, nervousness, irritability, and intense hunger. Other clinical signs are related to neuroglycopenia by a decrease in blood glucose, which stimulates the autonomic nervous system, causing hypothermia, lethargy, weakness, ataxia, collapse, muscular fasciculation, convulsions, and coma. The diagnosis of an insulin-secreting tumour requires confirmation of hypoglycemia with evidence of elevated insulin secretion and the identification of a pancreatic mass by ultrasonography or exploratory celiotomy. An insulin:glucose ratio $>30$ is indicative of insulinoma. Unfortunately, the specificity of the amended insulin:glucose ratio is poor. In the past, there has been confusion with respect to their biological nature, because, based on histological and electron microscopic evaluations, $60 \%$ of these neoplasms are carcinomas and $40 \%$ are adenomas. Nevertheless, these claims were not substantiated and most insulinomas are currently considered to be malignant (carcinomas). The objective of this paper was to present a rare case of a Boxer dog that had three $\beta$ cell tumours of the pancreas, which produced hyperinsulinemia and hypoglycemia. Although this is not a malignant tumour, we demonstrated, as described in the literature, that regardless of the histopathological classification, insulinproducing tumours have a poor prognosis in dogs.
\end{abstract}

Keywords: $\beta$ cell adenoma, hypoglycemia, insulinoma, seizures.

${ }^{1}$ Faculty of Veterinary Medicine and Zoothecnics, Universidad Michoacana de San Nicolás de Hidalgo (UMSNH), Morelia, Mexico. ${ }^{2}$ Private practice, Morelia, Mexico. ${ }^{3}$ University Veterinary Hospital, Veterinary Department, Universidad Autónoma de Ciudad Juárez (UACJ), Mexico. CORRESPONDENCE: C.A. Rodríguez-Alarcón [carrodri@ uacj.mx - Tel.: +52 6566881800 ext. 1664]. Veterinary Department, Universidad Autónoma de Ciudad Juárez. Anillo Envolvente del Pronaf y Estocolmo S/N. Zona Pronaf. C.P. 32310. Ciudad Juárez, Chihuahua, Mexico. 


\section{INTRODUCTION}

Insulinoma is the most frequent pancreatic tumour from insulin-secreting $\beta$ cells $[9,15]$. In $90 \%$ of cases, the tumour is a small, solitary, endocrinologically-active nodule, causing hypoglycemia secondary to hyperinsulinemia [18]. In the past, $60 \%$ of these neoplasms were considered to be carcinomas and $40 \%$ were adenomas. However, insulinomas are considered to have a high malignancy component [20].

Insulinoma is usually diagnosed in middle-aged or older dogs of medium to large breeds, such as Standard Poodles, Boxers, German Shepherds and Irish Setters, although it may occur in any breed $[6,16]$. The diagnosis of an insulin-secreting tumour requires confirmation of hypoglycemia, evidence of increased insulin secretion, and identification of a pancreatic mass by ultrasonography or exploratory celiotomy $[13,21]$. An insulin:glucose ratio $>30$ is indicative of insulinoma. Unfortunately, the specificity of this test is poor because dogs with other causes of hypoglycemia can also have abnormal ratios [3].

Partial pancreatectomy is the elective treatment; however, in animals with metastatic disease, surgery should only be performed for palliative reasons [10]. Median survival time of dogs treated with this surgery is 785 days. Dogs treated medically have a median survival of 196 days, and medically and surgically treated dogs have a median survival of 1316 days [16].

The aim of this study is to present a rare case of a Boxer dog that had three pancreatic $\beta$ cell adenomas, which produced hyperinsulinemia and hypoglycemia. We demonstrated, as described in the literature, that regardless of the histopathological classification, insulin-producing tumours have a poor prognosis in dogs.

\section{CASE}

An 8-year-old spayed female Boxer presented to the clinic for examination. The patient was spayed 5 years prior and her vaccination and deworming calendars were up to date. The patient lived with two other clinically-healthy dogs. Water and food consumption were normal, and she had normal micturition and defecation. Previous diseases were not reported.

The animal had three seizures over the previous three days. In addition, she showed a predromal period: nervousness, weakness and trembling, after which she presented with generalised tonic-clonic seizures and a loss of consciousness for 1 to $3 \mathrm{~min}$, from which she reincorporated confused; after 5 to $10 \mathrm{~min}$, she recovered completely, returning to a normal physical and mental state. On previous occasions (external veterinary clinic), the bitch had presented with hypoglycemia at 0.59 and $2.49 \mathrm{mmol} / \mathrm{L}$ (ranging from 3.9 to $6.64 \mathrm{mmol} / \mathrm{L}$ ).

During the physical examination, the patient was alert and responsive to external stimuli; she showed a body condition of $4 / 5$, according to the scale of Laflamme [5], and had a body weight of 42 $\mathrm{kg}$. Her physiological parameters were within normal ranges. No significant abnormalities were reported in the $\mathrm{CBC}$ and urinalysis. Contrarily, the biochemical analysis, reported hypercholesterolemia $(7.8 \mathrm{mmol} / \mathrm{L}$, ranging from 3.12 to $6.18 \mathrm{mmol} / \mathrm{L}$ ). Additionally, the animal presented with hyperproteinaemia $(81 \mathrm{~g} / \mathrm{L}$, ranging from 56.6 to $54.3 \mathrm{~g} / \mathrm{L}$ ), hyperphosphatemia ( $2.00 \mathrm{mmol} / \mathrm{L}$, ranging from 0.78 to $1.72 \mathrm{mmol} / \mathrm{L}$ ), hypoglycaemia $(3.50 \mathrm{mmol} / \mathrm{L}$, ranging from 3.90 to $6.64 \mathrm{mmol} / \mathrm{L})$ and a slightly elevated ALT (87 U/L range $<70 \mathrm{U} / \mathrm{L})$ and ALP (410, range $<189 \mathrm{U} / \mathrm{L})$. The dog had hyperinsulinemia ( 89.75 ranging from 5 to 20 $\mathrm{mU} / \mathrm{L}$ ), even after fasting. Finally, the insulin:glucose ratio was 59.8 (normal $<30$ ). An abdominal ultrasound (mode $\mathrm{B}$ ) revealed a $0.6 \times 0.86 \mathrm{~cm}$ hypoechoic mass on the left pancreatic lobe (Figure 1) and another hypoechoic mass near the same lobe.

The dog's owner was told to feed the patient 4 to 6 times a day with her normal diet, and if the trembling and nervousness were detected again, to orally administer honey as a source of glucose. The animal was referred to surgery for an exploratory celiotomy with the presumptive diagnosis of insulinoma. Before the surgery, slight hypoglycemia was reported (3.38 $\mathrm{mmol} / \mathrm{L}$ ranging from 3.90 to $6.64 \mathrm{mmol} / \mathrm{L}$ ). A 5-mL bolus of glucose at $50 \%$ was administered as described in the literature [11] and the animal was maintained on a continuous intravenous administration of fluids with $5 \%$ dextrose in Hartmann solution (Solución Combinación P.I. $\left.{ }^{\circledR}\right)^{1}$. Glucose peri-surgical monitoring was performed and normal values were reported.

During the exploratory celiotomy, two mesenteric masses next to the pyloric antrum and adjacent to the left pancreatic lobule were detected and removed $(1.7 \times 1.5 \mathrm{~cm}$ and $2 \times 1.3 \mathrm{~cm})$. During the same surgery, a third mass was localised and resected from the left pancreatic lobule $(1.1 \times 0.7 \mathrm{~cm})$ [Figure 2]. There was no macroscopic evidence of metastases in the liver, 
lymph nodules, or other organs. Fine-needle aspiration (FNA) of mesenteric lymph nodules did not show diagnostic material.

After surgery, glucose concentration was monitored every 30 to $60 \mathrm{~min}$ for the first 4 to $6 \mathrm{~h}$, and then every 2 to $4 \mathrm{~h}$ until glucose concentration stabilised. The animal fasted for $72 \mathrm{~h}$ post-surgery, and was administered ampicillin $(22 \mathrm{mg} / \mathrm{kg}$ IV every $\left.8 \mathrm{~h}\left[\text { Pentrexyl }^{\circledR}\right]^{2}\right)$, enrofloxacin $(2.5 \mathrm{mg} / \mathrm{kg}$ IV every $12 \mathrm{~h}\left[\text { baytril }^{\circledast}\right]^{3}$ ) and a fluid therapy of $5 \%$ dextrose in Hartmann solution, alternating with $0.9 \% \mathrm{NaCl}$ $\left(\text { Solución CS-PiSA }{ }^{\circledR}\right)^{1}$ at maintenance doses.

Postsurgical testing and clinical evolution

Four days after surgery, the dog went home. Blood glucose and serum insulin were measured 30 days post-surgery, resulting in normal values: 4.4 $\mathrm{mmol} / \mathrm{L}$ blood glucose, ranging from 3.9 to 6.64 $\mathrm{mmol} / \mathrm{L}$, and $35.62 \mathrm{mU} / \mathrm{L}$ insulin, ranging from 5 to 20 $\mathrm{mU} / \mathrm{L}$. At this time, the insulin:glucose ratio was 7.22.

The patient remained healthy until 560 days after surgery, after which she presented with episodes of seizures. The owner decided not to administer treatment for this new episode of seizures, resulting in the death of the patient at 575 days after surgery.

The histopathology results for the three masses were insular endocrine adenomas, which, in immunohistochemistry analyses, showed a strong and diffuse immunoreaction to insulin.

\section{DISCUSSION}

In humans and dogs, although rare, insulinomas are the most frequent pancreatic functioning islet cell tumours. These tumours produce signs related

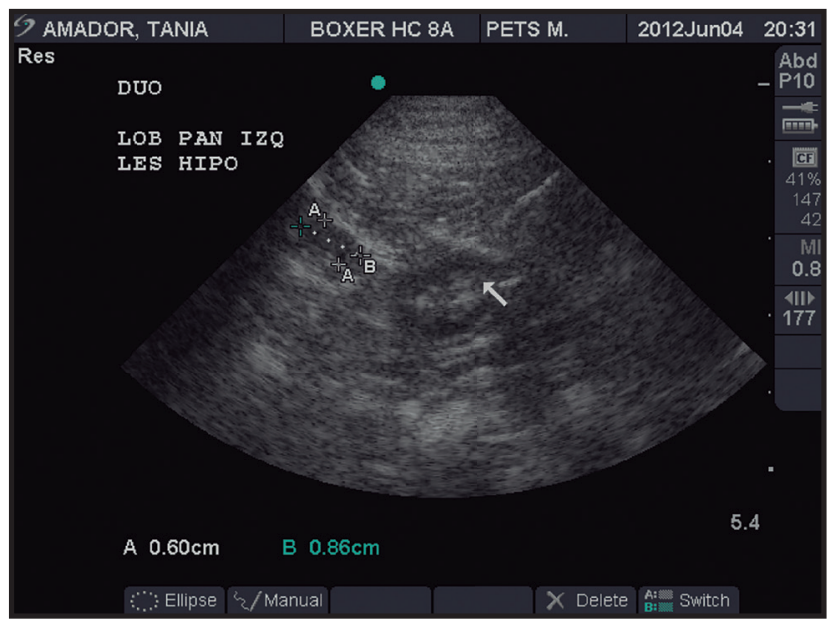

Figure 1. Ultrasonographic detection of a hypoechoic mass in the patient's left pancreatic lobe, delimited by the cross symbols (the white arrow points to the duodenum, transverse section). to hyperinsulinism, producing hypoglycemia, which is episodic and generally last from seconds to a few minutes due to regulatory compensatory mechanisms $[3,8,14,21]$. In dogs, clinical signs occur due to glucose deprivation of the central nervous system, which are categorised as neuroglycopenic symptoms. However, there are a number of adrenergic signs caused by catecholamines; dogs can display a combination of these signs [11]. Signs related to neuroglycopenia, which stimulates the autonomic nervous system, are hypothermia, lethargy, weakness, ataxia, collapse, muscular fasciculation, convulsions, and coma. If there is a fast decrease in blood glucose, hypothalamic glucoreceptors activate the sympathetic nervous system, producing signs such as tachycardia, tremors, nervousness, irritability, and intense hunger [3,21]. Generally, the most common sign in dogs with insulinoma is seizures [11]. Clinical signs are intermittent and they become more frequent as the disease progresses [21]; these signs are usually episodic and glucose administration quickly relieves them $[11,12]$. This is consistent with the present case, where the owner identified the seizure predromal phase, reporting the presence of episodes of tremors, nervousness, weakness, and generalised convulsions; these ceased to be present once glucose in the form of honey was administered to the patient, suggesting that the signs were due to hypoglycemia.

As in this clinical case, physical examination is unremarkable in most dogs with insulinomas. Obesity (4/5 body condition) was the only significant abnormality found in the general physical examination; excess weight has been described as being due to the

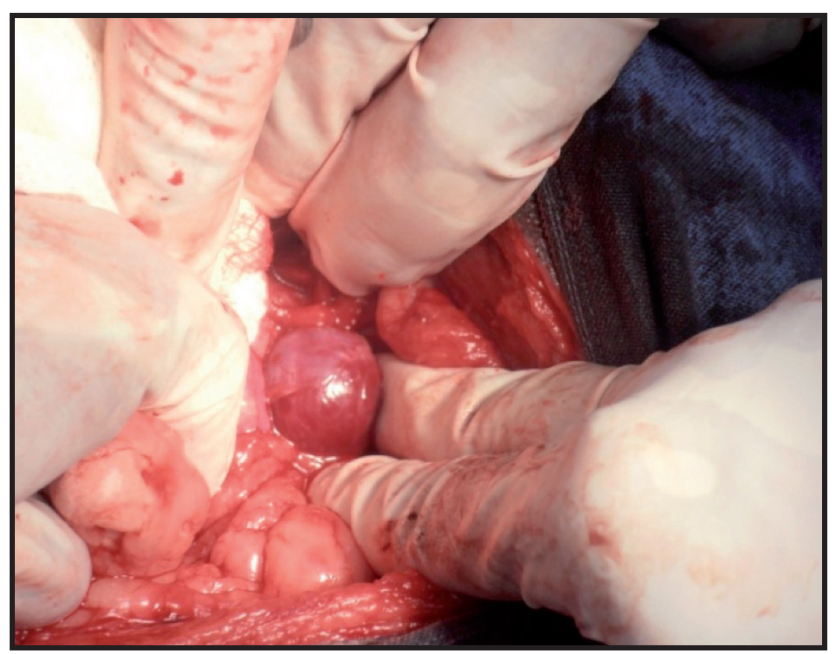

Figure 2. Perioperative photograph of a nodule localized in the left pancreatic lobule. 
anabolic effects of insulin, and the postictal effects in dogs with seizures [4,17].

The diagnosis of an insulin-secreting tumour requires confirmation of hypoglycemia, evidence of increased insulin secretion and identification of a pancreatic mass by ultrasonography or exploratory celiotomy [21]. An insulin:glucose ratio $>30$ is indicative of insulinoma. However, this test has low specificity because animals with hypoglycemia secondary to other causes could also have abnormal ratios [3]. In the present case, the test was efficient due to the evidence of hypoglycemia, which stabilised after the administration of honey; in addition, the initial insulin:glucose ratio was 59.8, and the ultrasound helped to identify the presence of masses in the pancreas, which justified the exploratory celiotomy, with a presumptive diagnosis of an insulin secreting $\beta$ cell tumour. This diagnosis was confirmed by the exploratory celiotomy and the histopathologic evaluation of the excised tissue.

Treatment for insulinomas should be directed to specific treatment for the tumour (surgical resection), reduction of the secretion of insulin and correction of hypoglycemia [12]. Treatment can be medical or surgical. Drugs such as prednisolone, diazoxide, octreotide and streptozotocin may be used as medical treatments for this disease [17]. Surgical resection of the pancreatic tumour and metastatic tumour masses is the treatment of choice; however, many animals present with evidence of metastatic disease at the time of the celiotomy and, in these cases, surgery should only be performed for palliative reasons [19]. In this case, exploratory celiotomy was chosen and no macroscopic evidence of metastases were found during the surgery. However, the dog had multiple masses, which is unusual as $75 \%$ of cases have been described as having a solitary tumour [7]. Dogs with insulinoma who underwent a partial pancreatectomy showed a median survival time of 785 days; dogs only treated medically had a median survival (MTS) of 196 days, whereas medically and surgically treated dogs had a MTS of 1316 days $[6,16]$. In this case, the patient remained clinically healthy until 560 post-surgical days, after which time clinical seizures relapsed, and she died at 575 days after surgery; this period of time is slightly less than average.

Prognosis for insulinoma is reserved because more than $95 \%$ of canine insulinomas are malignant and metastatic disease is already present in most pa- tients at the time of surgery [9]. Metastatic disease can be evaluated in two ways: macroscopic examination of the target organs during an exploratory celiotomy (liver and lymph nodules), or blood glucose stabilisation after surgery and after glucose infusion has been stopped [1]. However, even in a normal gross inspection, the liver and lymph nodes should be biopsied [11]. One limitation of this clinical case is that the target organs were not biopsied and the FNA for cytology was not diagnosed. However, as the dog had a final diagnosis of adenoma, it is unlikely to have metastasised, but the histopathological classification of the tumour was not important in this case; the prognosis and survival of dogs with insulinoma is similar in cases of carcinomas or adenomas.

In dogs, the classification of insulinomas as benign or malignant is based on their morphology. Pancreatic $\beta$ cell tumours are typically divided into adenomas or adenocarcinomas, but frequently, this division does not reflect their biological behaviour because the disease-free interval and survival time have been shown to be equivalent in dogs with adenomas and adenocarcinomas. Although histopathological studies remain important, the prognostic markers for canine insulinomas are tumour size, TNM stage (lymph node involvement and distant metastasis), presence of necrosis, and nuclear atypia [2]. In addition, an immunohistochemical biomarker, the Ki67 index, has proven to be an effective prognostic marker for canine insulinomas. Therefore, this biomarker and tumour size $(>2 \mathrm{~cm})$ are particularly influential parameters to determine patient survival [1,2]. In the present case, the animal presented with three tumours, and only one was $>2$ $\mathrm{cm}$, so it was classified as stage II.

Insulinomas are rare neoplasms in dogs, however, in cases of adult animals with a history of seizures, extracranial causes must be suspected, such as hypoglycemia secondary to this tumour. The signs of insulinomas are varied and nonspecific, and there are several tests to confirm or rule out the condition, including measuring serum glucose and insulin and determining the insulin:glucose ratio. However, a definitive diagnosis is made by exploratory celiotomy, resection of the tumour and the histopathological analysis of the tumour. Partial pancreatectomy is the treatment of choice, even if it is only palliative. 
Finally, a rare case of a pancreatic $\beta$ cell adenoma producing hyperinsulinemic hypoglycemia is presented. This has demonstrated a phenomenon that has been previously established: in insulinomas, the biological behaviour of malignant or benign tumours is similar, with both having the same reserved prognosis, disease-free time and equal short-term survival.
MANUFACTURERS

1PiSA Farmaceutica Mexicana. Guadalajara, Jalisco, Mexico.

${ }^{2}$ Bristol-Myers Squibb de México. Mexico City, Mexico

${ }^{3}$ Bayer de México. Mexico City, Mexico.

Declaration of interest. The authors report no conflicts of interest. The authors alone are responsible for the content and writing of the paper.

\section{REFERENCES}

1 Buishand F.O., M.G. van Erp, Groenveld H.A., Mol J.A., Kik M., Robben J.H., Kooistra H.S. Kirpensteijn J. 2012. Expression of insulin-like growth factor-1 by canine insulinomas and their metastases. The Veterinary Journal. 191(3): 334-340.

2 Buishand F.O., Kik M. \& Kirpensteijn J. 2010. Evaluation of clinico-pathological criteria and the Ki67 index as prognostic indicators in canine insulinoma. The Veterinary Journal. 185(1): 62-67.

3 Goutal C.M., Brugmann B.L. \& Ryan K.A. 2012. Insulinoma in Dogs: A Review. Journal of the American Animal Hospital Association. 48(3): 151-163.

4 Housley D. \& Tappin S. 2014. Canine insulinoma: part 1-diagnosis. Companion Animal. 19(3): 138-142.

5 Laflamme D. 1997. Development and validation of a body condition score system for dogs. Canine Practice. 22(4): $10-15$.

6 Leifer C.E., Peterson M.E. \& Matus R.E. 1986. Insulin-secreting tumor: diagnosis and medical and surgical management in 55 dogs. Journal of the American Veterinary Medical Association. 188(1): 60-64.

7 Lester N.V., Newell S.M., Hill R.C. \& Lanz O.I. 1999. Scintigraphic diagnosis of insulinoma in a dog. Veterinary Radiology and Ultrasound. 40(2): 174-178.

8 Lever-Rosas C.D., Enríquez-Pogan A., Chávez-Rodríguez J.J., Galván-González J.L. \& Cardona-Pérez M. 2001. Insulinoma. Informe de un caso. Revista de Sanidad Militar. 55(4): 170-173.

9 Madarame H., Kayanuma H., Shida \& R. Tsuchiya R. 2009. Retrospective Study of Canine Insulinomas: Eight Cases (2005-2008). Journal of Veterinary Medical Science. 71(7): 905-911.

10 Mcclaran J.K., Pavia P., Fischetti A.J. \& Donovan T.A. 2017. Laparoscopic Resection of a Pancreatic $\beta$ Cell Tumor in a Dog. Journal of the American Animal Hospital Association. 53(6): 338-345.

11 Meleo K.A. \& Peterson M.E. 2014. Treatment of insulinoma in Dogs, Cats, and Ferrets. In: Bonagura J. \& Twedt D. (Eds). Kirk's Current Veterinary Therapy XV. St Louis: Elsevier-Saunders, pp.130-134.

12 Morgan R.K., Cortes Y. \& Murphy L. 2018. Pathophysiology and aetiology of hypoglycaemic crises. Journal of Small Animal Practice. 59(11): 659-669.

13 Nakamura K., Lim S.Y., Ochiai K., Yamasaki M., Ohta H., MorishitaK., Takagi S. \& Takiguchi M. 2015. Contrastenhanced ultrasonographic findings in three dogs with pancreatic insulinoma. Veterinary Radiology and Ultrasound. 56(1): 55-62.

14 Okabayashi T., Shima Y., Sumiyoshi T., Kozuki A., Ito S., Ogawa Y., Kobayashi M. \& Hanazaki K. 2013. Diagnosis and management of insulinoma. World Journal of Gastroenterology. 19(6): 829-837.

15 Padovani L., Silva D.D., Moreira J.R., Cardoso M.J.L., Di Santis G.W. \& Zanutto M.S. 2017. Insulinoma canino: Relato de caso. Arquivo Brasileiro de Medicina Veterinaria e Zootecnia. 69(6): 1466-1472.

16 Polton G.A., White R.N., Brearley M.J. \& Eastwood J.M. 2007. Improved survival in a retrospective cohort of 28 dogs with insulinoma. Journal of Small Animal Practice. 48(3): 151-156.

17 Schoeman J.P. 2017. Insulin-Secreting Tumors. In: Ettinger S.J., Feldman E.C. \& Coté E. (Eds). Textbook of Veterinary Internal Medicine. 8th edn. St. Louis: Elsevier, pp.1762-1767.

18 Steiner J. \& Bruyette D.E. 1996. Canine insulinoma. Compendium on Continuing Education for the Small Animal Practitioner. 18(1): 13-23. 
19 Taye A. \& Libutti S. 2015. Diagnosis and management of insulinoma: current best practice and ongoing developments. Research and Reports in Endocrine Disorders. 5: 125-133.

20 Uwagie-Ero E.A., Awasum C.A., Onyejiakor C., Odigie E.A. \&Asemota D.O. 2017. Insulin-secreting $\beta$-cell neoplasia in a 7-year-old female dog, case report and review. Cogent Food \& Agriculture. 3(1): 1293467.

21 Vallee I.K. 2003. Insulin-secreting beta cell neoplasia in a 10-year-old dog. Canadian Veterinary Journal. 44(7): 592594. 